\title{
Pelatihan Pembuatan Abon dan Label Kemasan Produk Olahan Ikan Mas di RW. 07 Desa Ciasihan
}

\author{
Erneza Dewi Krishnasari ${ }^{1}$, Yaddarabullah ${ }^{2}$ \\ Telematika Fakultas Industri Kreatif, Universitas Trilogi, Indonesia ${ }^{1,2}$ \\ ernezadewi@trilogi.ac.id, yaddarabullah@trilogi.ac.id
}

ARTICLE INFO

Keywords:

Training

fish floss

visual identity design
ABSTRACT

Ciasihan Village is one of the villages in Pamijahan Sub-District, Bogo Regency. Most of the land is paddy field so that many residents work a farmers. But besides farming, the residents also have ponds for the cultivatio, of tilapia and carp. At the time of fish harvest, residents sell the fish withou being processed so the selling price tends to be low. To increase their income an effort is needed to increase the added value of the fish by processing it int fish floss. To sell the product, it must be packaged well so it is easy t. recognize and use. Based on this background, the empowerment given to th villagers of Ciasihan includes training on making the fish floss and makin. packaging labels. The purpose of this empowerment is not only to make foo, more durable, but also to provide a visual identity for the processed foo. products of Ciasihan Village.

\section{A. PENDAHULUAN}

Desa Ciasihan bagian dari kecamatan Pamijahan Kabupaten Bogor. Penduduk desa Ciasihan Di dalam desa terdapat 7 Rukun Warga. Kegiatan Pengabdian kepada Masyarakat dilakukan di RW 07. Pada RW 07 ini terdapat 2502 jiwa penduduk dengan 11708 jiwa berprofesi sebagai petani. Menurut data arsip desa (2010) Desa Ciasihan berdiri di atas lahan seluas $459.042 \mathrm{ha} / \mathrm{m} 2$, terbagi atas $55 \mathrm{ha} / \mathrm{m} 2$ luas pemukiman, sementara luas persawahan mencapai $342 \mathrm{ha} / \mathrm{m} 2$, sisanya adalah perkebunan, pemakaman, kolam ikan, dan sebagainya.

Pelatihan-pelatihan pengolahan makanan di Desa Ciasihan sebelumnya menitikberatkan pada pengolahan sayuran seperti membuat sayuran organic. Padahal ada potensi lain yaitu kolam-kolam ikan mas dan ikan nila yang dipelihara oleh warga. Pada saat panen ikan mas, biasanya para warga Desa Ciasihan langsung menjual ikan-ikan tersebut ke pasar tanpa diolah terlebih dahulu, sehingga nilai penjualannya tidak terlalu tinggi. Ikan merupakan bahan makanan yang lebih cepat mengalami pembusukan dibandingkan dengan bahan makanan lain disebabkan proses-proses kimiawi dan bakteri yang terkandung dalam ikan (Kusumayanti, dkk. 2011). Untuk itu ikan perlu diolah dahulu sebelum dijual. Hasil olahan ini dapat pula meningkatkan pendapatan dari warga Desa Ciasihan.

Abon adalah makanan yang terbuat dari serat daging hewan, baik ayam, sapi, maupun ikan. Karena kering dan hampir tidak memiliki kadar air, abon bisa tahan berbulan-bulan asalkan disimpan di wadah yang kedap udara. Abon dikatakan dapat meningkatkan daya jual serta memperpanjang umur bahan bakunya. (Heryanto, dkk., 2018)

Selain mengolah bahan dasarnya, perlu juga untuk mengemasnya dengan baik sehingga kualitas dan ketahanan pangan lebih terjaga. Fungsi kemasan bagi makanan salah satunya adalah untuk melindungi dan mengawetkan produk dan yang tak kalah penting, adalah agar produk tersebut memiliki ciri khas atau identitas visual (Syukrianti dan Nurif, M., 2015).

Oleh karena itu, pada kegiatan pengabdian masyarakat ini akan diberikan pelatihan pembuatan abon dengan bahan dasar ikan mas dan pelarihan pembuatan label kemasan untuk ibu-ibu warga Desa Ciasihan.

\section{B. METODOLOGI PELAKSANAAN}

Pengabdian kepada masyarakat dilaksanakan selama satu bulan bertempat di Universitas Trilogi dan di RW 07 Desa Ciasihan, Kec. Pamijahan, Kab. Bogor. Pelatihan pembuatan abon ikan mas 
menggunakan pendekatan praktek langsung, dimana mahasiswa dan warga Desa Ciasihan langsung mengerjakan apa yang diajarkan. Pelatihan ini terdiri dari 4 tahapan, seperti pada bagan di bawah ini:

\begin{tabular}{|c|c|c|c|c|}
\hline $\begin{array}{c}\text { Analisis } \\
\text { Kondisi dan } \\
\text { Potensi Desa }\end{array}$ & $\begin{array}{l}\text { Pelatihan } \\
\text { Desain } \\
\text { Kemasan }\end{array}$ & $\begin{array}{l}\text { Produksi } \\
\text { Kemasan }\end{array}$ & $\begin{array}{l}\text { Persiapan } \\
\text { Bahan } \\
\text { Pembuatan } \\
\text { Abon Ikan }\end{array}$ & $\begin{array}{l}\text { Pelatihan } \\
\text { Pembuatan } \\
\text { Abon Ikan }\end{array}$ \\
\hline
\end{tabular}

Gambar 1. Metode Pelaksanaan Pengabdian Masyarakat

\section{Analisis Kondisi dan Potensi Desa}

Pada tahap ini, tim pelaksana melakukan kunjungan ke Desa Ciasihan untuk mendata kondisi dan menganalisis potensi yang dapat dikembangkan, khususnya di RW 07. Hasil dari analisis data tersebut akan digunakan sebagai dasar dari menentukan pelatihan yang akan diberikan kepada masyarakat.

\section{Penentuan Jenis Kemasan}

Dari segi desain, kemasan memuat informasi-informasi tentang produk yang ada di dalam kemasan tersebut. Sedangkan dari segi fungsi, kemasan dapat digunakan untukmelindungi produk sehingga lebih tahan lama (Nugrahani, 2015). Terdapat beberapa jenis bahan untuk pengemasan sebuah produk, kemsan tradisional seperti daun pisang, kelobot jagung, daun jati, dan lain-lain; serta bahan kemasan modern yaitu kertas, aluminium foil, dan plastic (Santi, 2015) Menurut Samodro (2018), kemasan harus dirancang dengan baik agara dapat menarik bagi calon pembeli dengan memperhatikan:

1) Penampilan atau Daya Tarik visual

2) Bentuk kemasan

3) Warna

4) Kecenderungan pasar

\section{Pelatihan Desain Label Kemasan}

Setelah didapatkan hasil analisis potensi yang bisa dikembangkan di RW.07 Desa Ciasihan, serta penentuan jenis kemasan abon, tim pelaksana menentukan akan memberikan pelatihan pembuatan abon dari ikan mas. Tahap awal pelatihan ini dimulai dari pembuatan desain label pada kemasan.

Ada beberapa informasi yang dapat ditampilkan dalam label kemasan, yaiyu: Nama Produk, nama produsen, alamat produksi, komposisi, kandungan gizi, cara penggunaan,tanggal kadaluarsa, dan lain-lain (Rahmawati, 2013).

Perangkat lunak yang digunakan untuk merancang label adalah Microsoft Powerpoint 2013. Pelatihan desain kemasan ini mereferensi kepada metode desain yang telah disajikan pada program pengembangan teknopreneur (Yaddarabullah, Baskoro, Nurulhaq, \& Ramayanti, 2019)

\section{Produksi Kemasan}

Pada tahapan ini, tim pelaksana bersama mahasiswa memproduksi kemasan. Kemasan yang digunakan adalah berbentuk botol dengan bahan plastik dan memiliki kapasitas $80 \mathrm{mg}$. Kemasan ini diproduksi sebanyak 50 botol. Tujuan dari pemilihan botol sebagai kemasan yaitu agar abon ikan dapat bertahan lama dikarenakan kondisi botol yang kedap udara. Referensi desain kemasan menggunakan buku (Roesfitawati, 2017) dan artikel (Widodo, Octavia, Munib, Studi, \& Komunikasi, 2016).

\section{Produksi Label}

Menurut Agustina (2011) Dalam pencetakan label kemasan, perlu diperhatikan beberapa hal, yaitu: 
a. Label tidak boleh mudah dilepas dari kemasannya

b. Label harus ditempelkan pada tempat yang mudah dilihat

\section{Persiapan Bahan Pembuatan Abon Ikan}

Pada tahapan ini dilakukan pembelian bahan-bahan dasar untuk pembuatan abon ikan antara lain bawang merah, bawang putih, lengkuas, garam, sereh, minyak dan cabai. Ikan mas diperoleh dari kolam ikan yang dibudidayakan oleh warga RW 07 Desa Ciasihan. Referensi pembuatan abon ikan didapatkan dari buku (Handanari, Yuwono, Paulus, Azizah, \& Ramadhani, 2016) dan (Nurani \& Amar, 2011).

\section{Pelatihan Pembuatan Abon Ikan}

Pelatihan dilaksanan di gedung bina desa RW 07 Desa Ciasihan. Pelatihan ini menyasar kepada ibu-ibu rumah tangga dan remaja putri. Pelatihan dilaksanakan selama satu hari dengan dipandu dari awal menumis bumbu dasar dan ikan sampai dengan pengemasan abon.

\section{HASIL DAN PEMBAHASAN}

Hasil dari pelatihan pembuatan abon ikan ini antara lain menambah pengetahuan kepada masyarakat RW 07 Desa Ciasihan dalam mengolah salah satu ternak masyarakat yaitu ikan mas. Selain itu, dari pelatihan ini masyarakat juga mendapatkan pengetahuan untuk meningkatkan nilai tambah pada abon ikan mas yaitu dengan penerapan desain pada label kemasan. Berikut adalah pelaksanaan dari proses pelatihan pembuatan abon ikan mas.

\section{Pelatihan Pembuatan Desain Label Kemasan}

Pembuatan desain label kemasan diselenggatakan di Universitas Trilogi dengan melibatkan beberapa mahasiswa. Terdapat tiga desain yang dihasilkan, kemudian dilakukan penilaian oleh tim untuk ditentukan satu desain yang akan diimplementasikan pada kemasan.

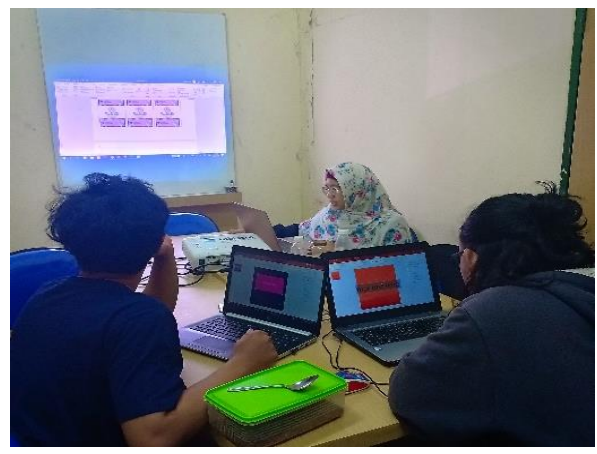

Gambar 2. Pelatihan Desain Label

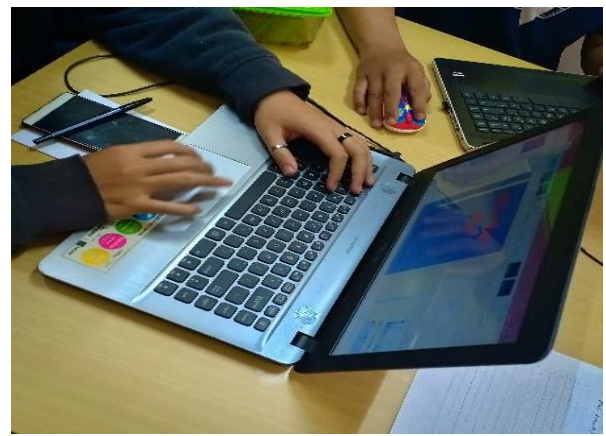

Gambar 3. Penilaian Desain Label

\section{Pengarahan Mengenai Produk Olahan}

Pengarahan dilakukan oleh dosen dari Program Studi Ilmu Teknik Pangan mengenai proses pembuatan abon dari ikan mas, cara menjaga kualitas dari abon dan penyajian pada saat dikonsumsi.

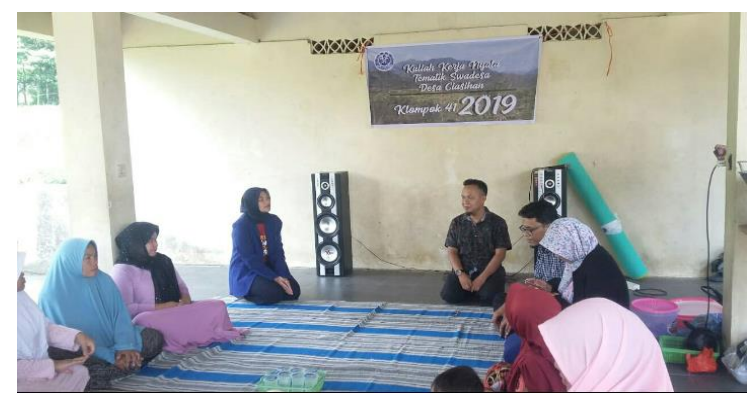

Gambar 4. Pengarahan Produk Olahan Pangan 


\section{Proses Memasak Ikan Mas Menjadi Abon}

Proses memasak ikan mas menjadi abon melibatkan ibu-ibu rumah tangga, remaja putri dan dibantu oleh beberapa mahasiswa yang sedang melaksanakan program kuliah kerja nyata (KKN). Proses memasak membutuhkan waktu kurang lebih dua jam dengan api kecil hingga kering.

Proses ini menggunakan proses yang konvensional (Balitbang Kelautan dan Perikanan, 2016) yaitu:

a. Serat daging ikan dibuat menggunakan sendik garpu atau ditumbuk, atau diparut.

b. Penggorengan ikan yang telah dicampur dengan bumbu dalam minyak panas selama kurang lebih 90 menit.

c. Meminimalisasi minyak hasil penggorengan abon ikan dengan dibungkus kain dan ditekan atau peras ulir.

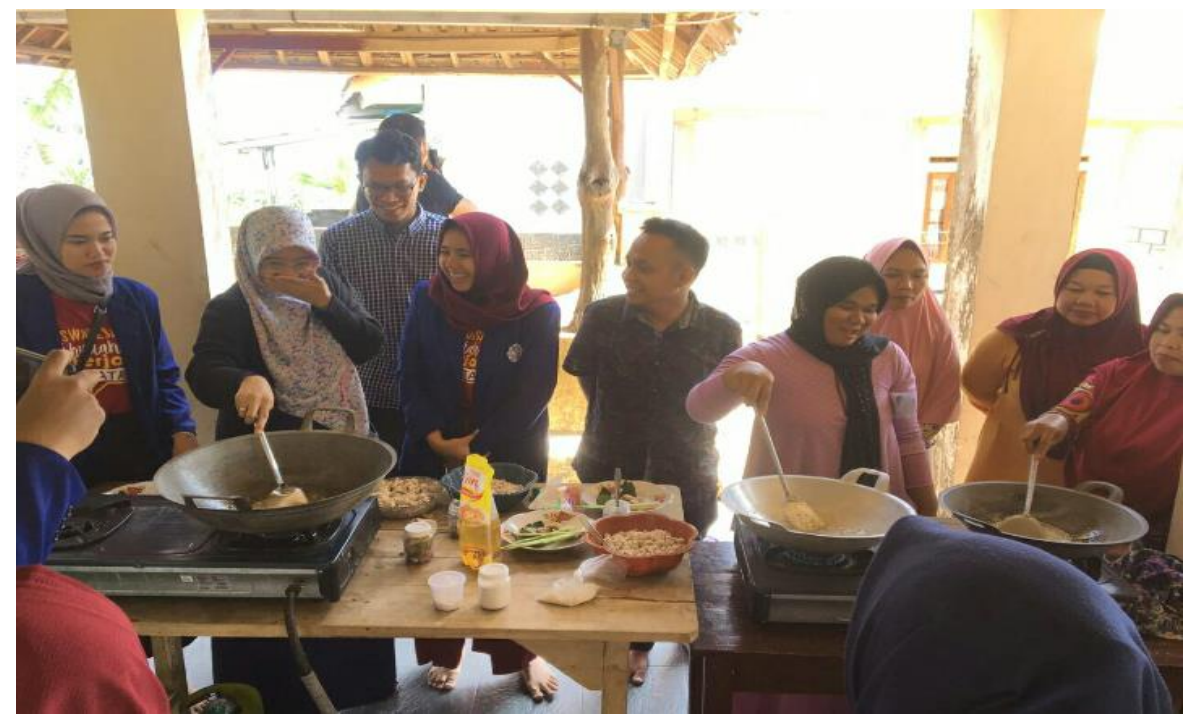

Gambar 5. Proses Memasak Ikan Mas Menjadi Abon

\section{Proses Pengemasan Abon Ikan}

Tahapan ini dilakukan setelah ikan mas yang digoreng menjadi abon dengan didinginkan selama satu jam. Semua peserta terlibat dalam mengemas abon kedalam botol yang telah disiapkan oleh tim mahasiswa.

Kemasan yang akan digunakan adalah botol plastik. Selain mudah didapatkan dan praktis, botol plastic dinilai cukup aman untuk penyimpanan abon dalam waktu yang lama ( Polutu, dkk, 2015)

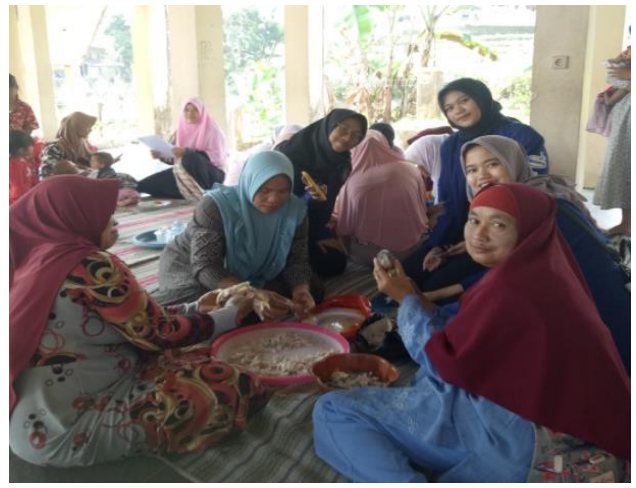

Gambar 6. Pengemasan Oleh Peserta

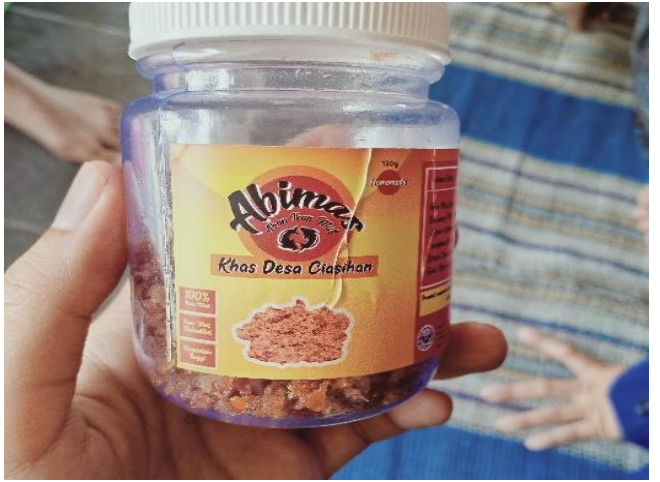

Gambar 7. Kemasan Abon Ikan mas 


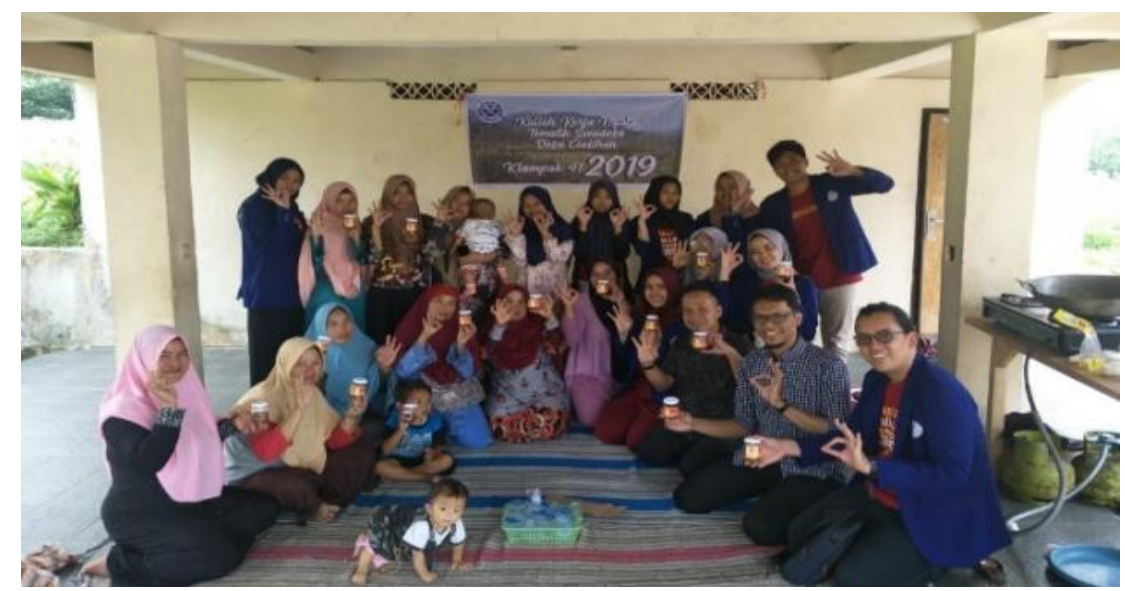

Gambar 8. Foto-foto Bersama Tim Pelaksana Pengabdian dan Peserta Pelatihan

\section{KESIMPULAN DAN SARAN}

\section{Kesimpulan}

Berdasarkan analisis terkait kondisi ekonomi dan keterlampilan masyarakat di RW 07 Desa Ciasihan maka dapat disimpulkan sebagai berikut :

1. Selain dari bertani, warga Desa Ciasihan terutama di RW 07 juga memiliki potensi ekonomi lain yaitu dari hasil ternak, khususnya ikan mas.

2. Masyarakat RW 07 Desa Ciasihan memasarkan hasil ternak ikan dengan cara dijual langsung ke pasar tanpa diolah terlebih dahulu.

3. Masyarakat RW 07 Desa Ciasihan belum mengetahui potensi ekonomi lainnya yang bisa didapatkan dari pengolahan dan pengemasan produk hasil ternak ikan.

4. Perlu diberikannya pelatihan berupa cara pengolahan dan pengemasan produk hasil ternak ikan. Salah satunya adalah dengan mengolah ikan menjadi abon ikan.

5. Perlu identitas visual dari produk olahan ikan tersebut, agar produk tersebut dapat dikenali darimana asalnya. Identitas visual ini tertuang dalam desain label kemasan. Pada label tersebut juga terdapat keterangan gizi dan bahan dari produk olahan ikan.

\section{Saran}

Setelah melaksanakan pelatihan pembuatan abon dari ikan mas kepada masyarakat RW 07 Desa Ciasihan, terdapat beberapa saran yang diberikan antara lain sebagai berikut :

1. Perlunya ada pelatihan desain label dengan software desain seperti Adobe Ilustrator atau Corel Draw, karena beberapa keterbatasan yang dimiliki oleh Ms Power Point yang bukan merupakan software khusus desain.

2. Perlunya pelatihan untuk strategi pemasaran, baik secara online maupun offline agar warga RW 07 memiliki pengetahuan tentang cara memasarkan produk mereka.

3. Warga perlu diperkenalkan dengan toko-toko yang dapat digunakan untuk menjual produkproduk mereka agar mendapatkan pesanan yang rutin dan berkelanjutan.

\section{Ucapan Terima Kasih}

Ucapan terima kasih disampaikan kepada warga RW 07 Desa Ciasihan, Ketua RW dan Kepala Desa yang telah membantu dalam memfasilitasi kegiatan pelatihan ini dalam rangka pelaksanaan salah satu tri dharma perguruan tinggi yaitu pengabdian kepada masyarakat. Terima kasih juga disampaikan kepada mahasiswa yang mengambil kuliah kerja nyata $(\mathrm{KKN})$ yang telah ikut serta membantu kegiatan inidan LPPM Universitas Trilogi yang telah mendukung dalam pendanaan dan memfasilitasi kebutuhan administrasi dengan Desa Ciasihan. 


\section{DAFTAR PUSTAKA}

Agustina, Wawan. 2011. Teknologi Pengemasan, Desain, dan Pelabelan Kemasan Produk Makanan. Lembaga Ilmu Pengetahuan Indonesia (LIPI). Subang

Badan Penelitian dan Pengembangan Kelautan dan Perikanan Kementrian Kelautan dan Perikanan. 2016. Rekomendasi Teknologi Kelautan dan Perikanan 2016. Jakarta: Kementrian Kelautan dan Perikanan

Handanari, T., Yuwono, T., Paulus, T. F., Azizah, N., \& Ramadhani, A. P. (2016). Rekomendasi Teknologi dan Perikanan. Jakarta: Badan Penelitian dan Pengembangan Kelautan dan Perikanan Kementrian Kelautan dan Perikanan.

Heryanto, F., Natadjaja L., dan Rika Febriani. 2018. Perancangan Desain Kemasan dan Media PRomosi Abon Ikan Asin UMK Sayu Sejahtera. Jurnal DKV Adiwarna vo;. 1 no. 12. Surabaya: Universitas Kristen Petra

Kusumayanti, H., Astuti, W., dan RTD Wisnu Broto. 2011. Inovasi Pembuatan Abon Ikan sebagai Salah Satu Teknologi Pengawet Ikan. Jurnal Gema Teknologi Vol. 16 no. 3. Semaran: Universitas Diponegoro

Mukhtar, Syukrianti dan Muchammad Nurif. 2015. Peranan Packaging dalam MEningkatkan Hasil Produlsi Terhadap Konsumen. Junral Sosial Humanioran Vol. 8 No. 2

Nugrahani, R. 2015. Peran Desain Grafis pada Label dan Kemasan PRoduk Makanan UKM. Jurnal Imajinasi Vol. IX no. 2. Semarang: Universitas Negeri Semarang

Nurani, D., \& Amar, A. (2011). Modul Pembelajaran Bindag Pangan Pengolahan Hasil Pertanian, Perikanan dan Kelautan. Jakarta: LP3M Institut Teknologi Indonesia.

Polutu, Kasumi A., Rieny SulistijowatiS, dan Faiza A. Dali. 2015. Pengaruh Jenis KEmasan dan Lama Penyimpanan pada Suhu Ruang terhadap Nilai TBA Abon Ikan Sidat. Jurnali Ilmiah Perikanan dan Kelautan Vol. 3 no. 4. Surabaya: Universitas Airlangga

Rahmawati, F. 2013. Pengemasan dan Pelabelan. Modul Pelatihan Kewirausahaan bagi Kelompok UPPKS BPPM DIY.

Roesfitawati. (2017). Desain Kemasan Produk Makanan Olahan. Jakarta: Direktorat Jendral Pengembangan Ekspor Nasional Kementrian Perdagangan.

Samodro (2018). Modul Mata Kuliah Desain Kemasan. Bintaro: Universitas Pembangunan Jaya

Santi, F.U. 2015. Teknik Pengemasan dan Labeling Produk Makanan. Makalah Pengabdian Masyarakat Desa Bejiharjo, Gunungkidul. Yogyakarta: Universitas Negeri Yogyakarta

Widodo, A. S., Octavia, E. R., Munib, J. A., Studi, P., \& Komunikasi, D. (2016). TEKNIK PERANCANGAN LABEL DAN KEMASAN PRODUK TEKSTIL KONVEKSI BAGI SISWA SMK DI SURAKARTA. Peningkatan Kapabilitas UMKM Dalam Mewujudkan UMKM Naik Kelas, 386-394.

Yaddarabullah, Y., Baskoro, L., Nurulhaq, B., \& Ramayanti, R. (2019). Kegiatan Inkubasi Bisnis Mengebangan Technopreneurship Di Kalangan Mahasiswa Universitas Trilogi. Jurnal Qardhul Hasan: Media Pengabdian Kepada Masyarakat, 5(1), 1-6. 